\title{
A selection index of multiple quantitative traits of the predator Cryptolaemus montrouzieri (Mulsant) (Coleoptera: Coccinellidae) through 12 inbreeding generations
}

Nadia Al-Khateeb ${ }^{1 *}$, Louai Asslan², Ghassan Ibrahim² ${ }^{2}$ and Ahmed El-Heneidy ${ }^{3}$

\begin{abstract}
Morphobiological indicators and selection index are helpful tools to obtain promising genotypes and selecting multiple traits for genetic improvement of the predator, Cryptolaemus montrouzieri (Mulsant) (Coleoptera: Coccinellidae). The present study was carried out at the Biological Control Department, Lattakia, Syria, during 2016. Three quantitative traits $(\mathrm{QTS})$, fecundity, preying potential of the $3^{\text {rd }}$ larval instar and larval developmental period, were studied through inbreeding program of 12 successive generations. The numerical changes of the (QTs) were studied across the generations and according to the three tested lines in comparison with control in order to determine the effect of each genetic line. Genetic parameters variances (phenotypic, genetic, environmental, phenotypic coefficient, genotypic coefficient, environmental coefficient, and broad-sense heritability) were estimated for each trait, separately and according to their approved lines, as well as the relative economic value of each trait involved in the design of the selection index equation. Obtained results showed that there were significant reductions in all the studied quantitative traits in the control, when (Po) was compared with (F12). Fecundity and reproduction showed the highest depression and response to the inbreeding program (42.28 and $46.93 \%)$, respectively. Statistical analyses of the fecundity line showed significant increases in length of the female, fecundity, and reproduction attained $(+9.53,+40.96,+37.78 \%)$, respectively, while significant decreases in all other quantitative traits, survival rate, preying potential of female, preying potential of the $3^{\text {rd }}$ larval instar, and larval developmental period, were recorded $(-2.09,-27.81,-15.84$, and $-11.10 \%)$, respectively. Results of the second line (preying potential of the $3^{\text {rd }}$ larval instar) showed significant reductions in all the studied quantitative traits except, preying potential of the $3^{\text {rd }}$ larval instar and preying potential of female recording $(+22.81$ and $+0.83 \%)$, respectively. The third genetic improvement line (larval developmental period) significantly increased only in the same trait (+23.83\%), while there were significant decreases in all others. Obtained results revealed that broader sense heritability of the three quantitative traits attained $47.43,31.66$, and $17.66 \%$, respectively in the control, increased to 63.70 , 40.80, and $33.50 \%$ in the three genetic lines of each trait, respectively. A selection index (index weights of the quantitative traits) was calculated. The application of this selection index is necessary to apply it in the genetic improvement programs in order to increase the efficacy of the predator breeding.
\end{abstract}

Keywords: Cryptolaemus montrouzieri, Inbreeding, Genetic parameters, Quantitative traits, Broad sense heritability, Selection index

\footnotetext{
*Correspondence: nadia4@scs-net.org; nadia@arabscientist.org

${ }^{1}$ Directorate of Agriculture, Department of Biological Control, Lattakia Center

for Rearing Natural Enemies, P. O. Box 2012, Lattakia, Syria

Full list of author information is available at the end of the article
} 


\section{Background}

The mealy bug ladybird, Cryptolaemus montrouzieri (Mulsant) (Coleoptera: Coccinellidae), is one of the most important biological control agents that preys upon a wide range of mealy bug species in many parts of the world (Simmonds et al. 2000). Both larvae and adults feed on all stages of mealy bugs, (Jayaraman et al., 1988). The first introduction of this ladybird for biological control dates back to 1891 when Albert Koebele brought it into California for control of Planococcus citri Risso (Bartlett 1974). Since then, the beetle has been introduced into several countries in biological control programs with varied success (Dixon 2000). The predator was introduced to Turkey from the USA in 1965 to control P. citri on citrus trees (Oncuer and Bayhan 1982), and it was introduced to Syria from Turkey in 1995; since then, it is reared at the Lattakia Center for Rearing Natural Enemies, Tartous Research Center and Biological Control Studies and Research Center. Rearing program of the predator in Syria aims to mass rear and release it periodically during the season to control citrus mealy bug in the western coast of Syria (Al-Khateeb and Asslan 2007; Al-Khateeb et al. 2012; Al-Khateeb and Raie 2002).

Population ecology is an essential component in the practical application of natural enemies in controlling pests, but the importance of genetics and adaptive evolution in biological control remains a controversial topic (Hufbauer and Roderick 2005; Phillips et al. 2008). The genetically improved natural enemies (predators, parasitoids and pathogens) might be the next level biological weapons against the pest populations in agricultural systems (Routray et al. 2016). Therefore, genetics research on insect natural enemies is rare and basically limited to parasitoid wasps and a few predators. The understanding of inbreeding is one of these genetic bases because traits may deteriorate rapidly through inbreeding (Jervis 2007). During the production phase of insects in the laboratory, some individuals can contribute randomly to the next generation more than others and this sampling effect can lead to a random loss of some alleles in each generation. This process is called a genetic drift and can lead to a substantial reduction in the genetic variability within the reared population. Therefore, inbreeding program is necessary as the first step to begin the genetic improvement programs because it is the most effective in increasing the levels of homozygosity and increasing the frequency of wanted and unwanted alleles and to increase the effectiveness of genetic selection (Jervis 2007). Estimation of genetics parameters of quantitative traits of the target species is necessary to create an artificial selection and expressed in values. The phenotypic value of an individual can be measured relative to the population mean, and the genetic structure of a population refers to the amount and distribution of genetic variations within and between populations (McDonald 1997). If the variation in a quantitative trait is, at least in part, genetically determined, then offspring should resemble their parents.

The heritability $\left(h^{2}\right)$ (the broad-sense heritability) is the most important genetic value. It is the ratio between the genetic variance and the total phenotypic. The general effect of the environment may seriously bias estimates of genetic variances and heritability. The estimation of $h^{2}$ is necessary to establish an artificial selection or selection index. Artificial selection has been suggested as a method of improving the effectiveness of the natural enemies during mass-rearing (Rutledge and Wiedenmann 2003). Hazel (1943) introduced the analytical method for calculating a selection index. Creating an artificial selection contributes to estimate the relative economic values of the economically important traits, where the selection is based on the final outcome of the important traits and allows an excellent trait to cover the defects in another lower quality trait. Literature shows that the selected index is one of the helpful tools in this process, because it allows multiple traits to be selected simultaneously.

Due to the rarity of genetic studies related to $C$. montrouzieri and no selection index of it was reported before, this study was carried out to create an artificial selection of the most important economic characteristics: fecundity, preying potential of the $3^{\text {rd }}$ larval instar, and larval developmental period which may contribute to raising the indicators of the biological efficacy of the predator.

\section{Materials and methods} Rearing of Planococcus citri (Risso)

The potato was used as a host for P. citri. Successful rearing required using a suitable variety of potato; Sponta has proved to be one of the best varieties for rearing $P$. citri, due to its ability to withstand the conditions of storage, speed to break dormancy stage at a temperature of $4 \pm 1{ }^{\circ} \mathrm{C}$ and speed giving branches in a short period. The potatoes were kept under a dark condition, at a temperature of $10-12{ }^{\circ} \mathrm{C}$ and $60 \pm 10 \% \mathrm{RH}$ inside plastic containers until branches reach $10-15 \mathrm{~cm}$. P. citri was a preferable insect prey species because of its short life cycle and its fecundity under the conditions of $25 \pm 2{ }^{\circ} \mathrm{C}, 60 \pm 10 \% \mathrm{RH}$, and 16:8 light to dark (L:D), using the same plastic containers. Potato stems (10$15 \mathrm{~cm}$ long) were prepared to be infested with $P$. citri, using slices of smooth, clean papers, and placed on $P$. citri. The leaves were transferred to darkness to obtain new growths. Repetition of this process was undertaken twice a day to get a pure infestation. Thirty to 45 days were needed to reach the complete infestation and obtaining different instars of $P$. citri. 


\section{Rearing of Cryptolaemus montrouzieri Mulsant}

The techniques of Smith and Armitage (1931) and Whitcomb and Bell (1964) for rearing C. montrouzieri were followed. Adults of the predator were released on the branches of infested potatoes with $P$. citri, under the conditions of $25 \pm 2{ }^{\circ} \mathrm{C}$ temperature, $60 \pm 10 \% \mathrm{RH}$, and $16: 8$ light to dark (L:D), inside the same plastic containers.

\section{First parental laboratory generation (Po)}

The experiments were carried out (with 30 replicates), using a glass cage $(2 / 1)$, covered with a soft cloth. Each cage had 2 tubers of potato, infested with P. citri and one pair $(1 \hat{\delta}+1$ 우 of C. montrouzieri, isolated from the stock culture, to establish the first parent generation (Po). The cages were placed in an incubator under the conditions of $25 \pm 2{ }^{\circ} \mathrm{C}, 60 \pm 10 \% \mathrm{RH}$, and $16: 8$ light to dark (L:D); after hatching of C. montrouzieri newly larvae in the containers, 30 newly hatched larvae were isolated from each replicate and then transferred to Petri dishes with the branches of potatoes infested with $P$. citri to develop to $C$. montrouzieri adults in order to study the morphobiological parameters of the predator.

\section{Genetic improvement lines of the predator}

1. The control line. The paternal pair was chosen randomly for each replicate at the beginning of each generation, from the previous generation, through the inbreeding 12 generation program.

2. The first quantitative trait (fecundity). The selection was based on one quantitative trait assumed to be polygenic (female fecundity (Fec.)). The parent pair was selected according to the highest fecundity of female.

3. The second quantitative trait (preying potential of the $3^{\text {rd }}$ larval instar). The selection was based on the quantitative trait (preying potential, potential of the $3^{\text {rd }}$ larval instar (PPLI)). The parent pair was selected for the next generation, according to the highest preying potential of the $3^{\text {rd }}$ larval instar.

4. The third quantitative trait (larval developmental period). The selection was based on the quantitative trait (larval developmental period (LdP)). The parent pair was selected for the next generation, according to the highest (larval developmental period).

All traits + the control consisted of 30 replicates/ each, and the selection was conducted in order to improve and increase this trait through the 12 inbreeding generations and to calculate its economic value to be included in the selection index. Morphobiological indicators in all lines were calculated at the end of Po, F1, F3, F6, and F12.
1. Genetic parameters were calculated at the end of F12.

2. Correlation relationships were calculated in Po and F12 in the control.

\section{Calculated morphobiological parameters}

1. Length of female: by using millimeter lens.

2. Fecundity: calculation based on the number of the newly hatched larvae.

3. Reproduction: number of adults produced by one female.

4. Survival rate: reproduction/fecundity $\times 100$.

5. Preying potential of adults for female (P. citri nymphs/day). One hundred nymphs $/ 3^{\text {rd }}$ nymphal instars of $P$. citri were kept in Petri dishes (9-mm diameter), 30 replicates for females, for each generation and for each line. The Petri dishes were checked daily, and the number of nymphs consumed by C. montrouzieri individual was recorded in 3 days, and then the average daily predation rate was recorded.

6. Preying potential of $3^{\text {rd }}$ larval instar: by the same way was recorded.

7. Developmental period: the period (days) from eggs to adults.

8. Larval developmental period: the period (days) from hatching 1 st larval instar to the pupation.

\section{Experimental design and statistical analysis}

Experiments were carried out using the Randomized Complete Block Design. Obtained data were subjected to ANOVA test, using the computer software package SPSS V.18 to determine Duncan's multiple range tests at probability $1 \%$. Parameter response for each line of genetic improvement of the predator at the end of the 12th generation was calculated as follows:

Inbreeding depression/parameter response $=[(\mathrm{F} 12-\mathrm{P} 0) /$ F12] $\times 100$ (Oupadissakoon and Wersman 1977).

\section{Estimation of genetic parameters}

- Genetic, phenotypic, and environmental variances were calculated according to the following formulas:

$$
\begin{aligned}
\mathrm{VP} & =\mathrm{VG}+\mathrm{VE} \\
\mathrm{VE} & =\mathrm{MSE} \\
\mathrm{VG} & =(\mathrm{MST}-\mathrm{MSE}) / \mathrm{r}
\end{aligned}
$$

where VP is the phenotypic variance, VG is the genetic variance, $\mathrm{VE}$ is the environmental variance, $R$ is the number of replications for each generation, MST are the 
mean squares between groups (between generations), and MSE are the mean squares within groups (error).

- Broad sense heritability $h^{2}$ bs $=$ VG/VP $\times 100$ (4). Formulas (1), (2), (3), and (4) were estimated according to (Falconer 1989).

- To compare the variations among traits, phenotypic coefficient of variation (PCV), genotypic coefficient of variation $(\mathrm{GCV})$, and environmental coefficient of variation (ECV) were computed, according to the method suggested by Singh and Chaudhary (1985) $(5,6,7): \mathrm{PCV}=(\sqrt{ } \mathrm{Vp} / X) 100(5), \mathrm{GCV}=(\sqrt{ } \mathrm{Vg} /$ X) 100 (6), and $\mathrm{ECV}=(\sqrt{ } \mathrm{Ve} / X) 100(7)$

Where $X$ is the grand mean for each of the studied traits.

- Artificial selection (selection index) was calculated according to the following formulas: $I=\mathrm{b} 1 \mathrm{x} 1+\mathrm{b} 2 \times 2$ + b3x3 (Hazel 1943)

where $I$ is the index value and b1, b2, and b3 are economic values (index weights) of the quantitative traits (fecundity, preying potential of the $3^{\text {rd }}$ larval instar, larval developmental period), respectively. $x 1, x 2$, and $x 3$ are phenotypic information sources and refer to the same quantitative traits.

- Economic value $(b)$ was calculated according to the following formula:

$$
b=P^{-1} G v
$$

where $P^{-1}$ is the inverse of the phenotypic variance, $G$ is a matrix of the genetic variance, and $v$ is the relative economic values of objective traits. Relative economic values were calculated according to fecundity trait as the primary trait.

\section{Results and discussion}

Changes in morphobiological parameters of $C$. montrouzieri for 12 inbreeding generations

Results in Table 1 and Figs. 1, 2 and 3 showed that there were significant decreases in all quantitative traits under control line, the numerical value of the female length decreased from $4.58 \mathrm{~mm}$ in Po to $4.13 \mathrm{~mm}$ in F3, and insignificant decrease between F3 and F6, F9, and F12, which confirms that three generations of inbreeding were sufficient to reflect the values depression of this trait due to increased expression of recessive alleles and the inbreeding depression recorded $(-16.81 \%)$.

Fecundity was more affected by the control line (Fig. 1), decreased significantly from 134.97 in Po to 107.83 in F3, and continued a significant depression to F9. It was 87.90 less than the insignificant decrease at F12. Thus, fecundity trait required nine inbreeding generations to express its response to the pattern of inbreeding recording $(-42.28 \%)$ at the end of F12.

For the reproduction, the value of this trait decreased significantly from 121.97 in Po to 93.57 in F3 and continued this regression to 80.03 in F6. F6 was an equilibrium point because the differences were insignificant between F6 and each of F3, F9, and F12 and six inbreeding generations were sufficient to express its response to the control line, recording $(-46.93 \%)$ at the end of F12.

As well, the survival rate decreased significantly from $89.74 \%$ in Po to $86.41 \%$ in F3, with insignificant differences between F3 and each of F9 and F12 and inbreeding depression recording $(-7.66 \%)$ at the end of F12.

The results showed that the preying potential of the $3^{\text {rd }}$ larval instar (Fig. 2) recorded significant differences during the studied generations. It decreased significantly from 27.06 larvae/day in Po to 21.42 larva/day at F12 with a response $-20.84 \%$. As for the preying potential of female, six generations of inbreeding were sufficient to express their response to the inbreeding line, recording (21.71\%) at the end of F12. The larval developmental period (Fig. 3) decreased significantly from 14.87 day in Po to 12. 63 day at F12 and the response was $-15.06 \%$. Developmental period was characterized by equilibrium and stability from Po to F12 with insignificant differences during the studied generations. The response recorded $(-1.31 \%)$.

\section{Changes in morphobiological parameters of $C$. montrouzieri for the first genetic improved line/the first quantitative trait (fecundity), through inbreeding in 12 generations}

Results in Table 1 and Figs. 1, 2 and 3, for fecundity improvement in lines within inbreeding program of the predator, showed that the length of female increased significantly from $4.51 \mathrm{~mm}$ in Po to $4.90 \mathrm{~mm}$ in F3, while its height was stabilized until the end of F12, with insignificant differences. This increase in the value of this indicator was offset by the depression in the control line and for three generations, which confirms that the female length needed three generations of successive breeding to reflect the alleles isolation of this trait, the female length response for this improvement line in F12 was $(+9.53 \%)$, with significant differences from the control line $(-16.81 \%)$. Which confirms that the improvement of fecundity had led to improve the length female due to the positive correlation between them $(r=0.81$ in Po and $r=0.63$ in F12) (Tables 1 and 2).

For the fecundity, it responded to the line of recurrent selection from the first isolation generation F1 to F12. The fecundity increased significantly from 138.20 in Po to 157.83 at F1 to 171.90 at F3 (Table 1). In F6, fecundity recorded 182.90 with insignificant differences with F9 and significant differences with F12. Response recorded $+40.96 \%$. It was almost equal to the inbreeding 
Table 1 Changes in morphobiological parameters (mean \pm SD) of the predator C. montrouzieri for 12 inbreeding generations using three genetic improved lines

\begin{tabular}{|c|c|c|c|c|c|}
\hline Parameter & Generations & Control line & $\begin{array}{l}\text { First genetic improved } \\
\text { line } \\
\text { (Fec.) }\end{array}$ & $\begin{array}{l}\text { Second genetic improved } \\
\text { line } \\
\text { (PPLI) }\end{array}$ & $\begin{array}{l}\text { Third genetic improved } \\
\text { line } \\
(\mathrm{LdP})\end{array}$ \\
\hline \multirow[t]{6}{*}{ Female length (mm) } & Po & $4.58 \pm 0.41$ a $A$ & $4.51 \pm 0.48 \mathrm{~b} \mathrm{~A}$ & $4.64 \pm 0.26$ a A & $4.49 \pm 0.50$ a $A$ \\
\hline & F1 & $4.32 \pm 0.53 \mathrm{ab} B$ & $4.68 \pm 0.25 \mathrm{~b} \mathrm{~A}$ & $4.33 \pm 0.37 b$ B & $4.27 \pm 0.44 a b B$ \\
\hline & F3 & $4.13 \pm 0.56 \mathrm{bc} B$ & $4.90 \pm 0.25$ a A & $3.95 \pm 0.55$ c B & $3.99 \pm 0.39 b c B$ \\
\hline & F6 & $3.97 \pm 0.50 \subset B$ & $4.91 \pm 0.31$ a A & $3.86 \pm 0.66$ c B & $3.81 \pm 0.41 \mathrm{CB}$ \\
\hline & F9 & $3.90 \pm 0.39 c B$ & $4.93 \pm 0.27$ a A & $3.94 \pm 0.37$ c B & $3.93 \pm 0.31 \mathrm{CB}$ \\
\hline & $\mathrm{F} 12$ & $3.81 \pm 0.45 \mathrm{CB}$ & $4.94 \pm 0.26$ a A & $3.89 \pm 0.48$ c B & $3.83 \pm 0.44 \mathrm{CB}$ \\
\hline $\begin{array}{l}\text { ID\%/parameter response for } \\
\text { each line at the end of } 12 \text { th }\end{array}$ & & -16.81 & +9.53 & -16.16 & -14.70 \\
\hline \multirow[t]{6}{*}{ Fecundity } & Po & $\begin{array}{l}134.97 \pm 31.68 \mathrm{a} \\
\mathrm{A}\end{array}$ & $138.20 \pm 21.88 \mathrm{fA}$ & $131.40 \pm 39.76$ a A & $149.70 \pm 35.89$ a A \\
\hline & $\mathrm{F} 1$ & $\begin{array}{l}126.87 \pm 33.43 a \\
B\end{array}$ & $157.83 \pm 15.03 \mathrm{~d} A$ & $124.67 \pm 34.47 a b B$ & $128.53 \pm 39.12 b$ B \\
\hline & F3 & $\begin{array}{l}107.83 \pm 22.46 b \\
B\end{array}$ & $171.90 \pm 14.13 \mathrm{c} \mathrm{A}$ & $108.23 \pm 36.47 \mathrm{bc} \mathrm{B}$ & $113.83 \pm 25.77 \mathrm{bcB}$ \\
\hline & F6 & $\begin{array}{l}94.77 \pm 15.77 b c \\
B\end{array}$ & $182.90 \pm 13.50 \mathrm{~b} \mathrm{~A}$ & $99.23 \pm 24.70$ c B & $98.47 \pm 19.73$ c B \\
\hline & F9 & $\begin{array}{l}87.90 \pm 13.32 \mathrm{~cd} \\
\text { B }\end{array}$ & $187.93 \pm 13.25 \mathrm{ab} A$ & $96.77 \pm 24.81$ c B & $97.17 \pm 22.10$ c B \\
\hline & F12 & $\begin{array}{l}78.07 \pm 12.75 d \\
C\end{array}$ & $194.80 \pm 15.45$ a A & $95.07 \pm 16.86$ c B & $95.37 \pm 16.13$ c B \\
\hline $\begin{array}{l}\text { ID\%/parameter response for } \\
\text { each line at the end of } 12 \text { th }\end{array}$ & & -42.28 & +40.96 & -27.65 & -36.29 \\
\hline \multirow[t]{6}{*}{ Reproduction } & Po & $\begin{array}{l}121.97 \pm 32.73 a \\
A\end{array}$ & $126.43 \pm 23.94 \mathrm{~d} A$ & $117.80 \pm 39.16$ a A & $137.90 \pm 38.78$ a A \\
\hline & F1 & $\begin{array}{l}113.63 \pm 34.44 a \\
B\end{array}$ & $142.67 \pm 17.88 \mathrm{CA}$ & $110.80 \pm 35.31 \mathrm{ab} B$ & $113.77 \pm 41.07 \mathrm{~b} \mathrm{~B}$ \\
\hline & F3 & $\begin{array}{l}93.57 \pm 21.84 b \\
B\end{array}$ & $157.33 \pm 14.63 \mathrm{~b} \mathrm{~A}$ & $92.97 \pm 37.79$ bc B & $96.40 \pm 29.99$ bc B \\
\hline & F6 & $\begin{array}{l}80.03 \pm 15.85 b c \\
\text { B }\end{array}$ & $165.77 \pm 14.42 \mathrm{ab} A$ & $82.15 \pm 28.02$ c B & $78.50 \pm 26.83$ c B \\
\hline & F9 & $73.20 \pm 14.92$ c B & $166.67 \pm 14.96 \mathrm{ab} A$ & $80.53 \pm 24.87$ c B & $76.73 \pm 20.75$ c B \\
\hline & $\mathrm{F} 12$ & $\begin{array}{l}64.73 \pm 11.71 c \\
C\end{array}$ & $174.20 \pm 13.96$ a A & $78.03 \pm 17.89$ & $75.40 \pm 17.78$ c B \\
\hline $\begin{array}{l}\text { ID\%/parameter response for each } \\
\text { line at the end of } 12 \text { th generation }\end{array}$ & & -46.93 & +37.78 & -33.76 & -45.32 \\
\hline \multirow[t]{6}{*}{$\%$ Survival rate } & Po & $\begin{array}{l}89.74 \pm \pm 3.79 a \\
A\end{array}$ & $91.12 \pm 3.86$ a A & $88.63 \pm 7.57$ a A & $91.24 \pm 5.22 \mathrm{a} \mathrm{A}$ \\
\hline & $\mathrm{F} 1$ & $88.75 \pm 4.09$ a A & $90.21 \pm 3.95$ a A & $87.90 \pm 6.82$ a A & $87.12 \pm 6.76 \mathrm{ab} \mathrm{A}$ \\
\hline & F3 & $\begin{array}{l}86.41 \pm 4.54 a b \\
A\end{array}$ & $91.5 \pm 3.23$ a A & $84.53 \pm 7.66$ ab A & $83.62 \pm 8.75 b c$ A \\
\hline & F6 & $84.19 \pm 5.36$ b B & $90.61 \pm 3.48$ a A & $82.15 \pm 9.32$ b BC & $78.13 \pm 12.32$ c C \\
\hline & F9 & $83.04 \pm 7.81$ b B & $88.68 \pm 4.56$ a A & $82.55 \pm 6.55$ b B & $78.82 \pm 8.02$ c B \\
\hline & $\mathrm{F} 12$ & $82.87 \pm 6.82$ b B & $89.22 \pm 5.62$ a A & $81.71 \pm 7.42$ b B & $78.38 \pm 9.42$ c B \\
\hline \multicolumn{2}{|l|}{$\begin{array}{l}\text { ID\%/parameter response for each line } \\
\text { at the end of } 12 \text { th }\end{array}$} & -7.66 & -2.09 & -7.81 & -14.09 \\
\hline \multirow{2}{*}{$\begin{array}{l}\text { Preying potential of } 3^{\text {rd }} \text { larval instar } \\
\text { (P. citri nymphs/day) }\end{array}$} & Po & $27.06 \pm 3.45 \mathrm{a} \mathrm{A}$ & $24.69 \pm 3.45$ a A & $24.20 \pm 3.41 \mathrm{~d} \mathrm{~A}$ & $27.73 \pm 2.23$ a A \\
\hline & $\mathrm{F} 1$ & $25.32 \pm 2.78 \mathrm{ab}$ & $23.33 \pm 2.55 a b B$ & $25.46 \pm 2.92 \mathrm{~cd} \mathrm{~A}$ & $26.42 \pm 3.10 \mathrm{ab} \mathrm{A}$ \\
\hline
\end{tabular}


Table 1 Changes in morphobiological parameters (mean \pm SD) of the predator C. montrouzieri for 12 inbreeding generations using three genetic improved lines (Continued)

\begin{tabular}{|c|c|c|c|c|c|}
\hline Parameter & Generations & Control line & $\begin{array}{l}\text { First genetic improved } \\
\text { line } \\
\text { (Fec.) }\end{array}$ & $\begin{array}{l}\text { Second genetic improved } \\
\text { line } \\
\text { (PPLI) }\end{array}$ & $\begin{array}{l}\text { Third genetic improved } \\
\text { line } \\
(\mathrm{LdP})\end{array}$ \\
\hline & F3 & $\begin{array}{l}23.77 \pm 2.86 b c \\
B\end{array}$ & $21.88 \pm 2.41 \mathrm{bc} \mathrm{C}$ & $27.03 \pm 2.20 \mathrm{bc} \mathrm{A}$ & $24.78 \pm 3.45 a b c B$ \\
\hline & F6 & $\begin{array}{l}22.29 \pm 3.06 \mathrm{~cd} \\
B\end{array}$ & $20.52 \pm 3.35$ c C & $28.04 \pm 1.73 \mathrm{~b} \mathrm{~A}$ & $24.67 \pm 3.42 a b c B$ \\
\hline & F9 & $\begin{array}{l}21.80 \pm 3.44 \mathrm{~cd} \\
\mathrm{C}\end{array}$ & $20.72 \pm 3.17$ c C & $28.18 \pm 1.83 a b$ A & $23.80 \pm 2.40 \mathrm{c} \mathrm{B}$ \\
\hline & F12 & $21.42 \pm 3.25 \mathrm{~d} C$ & $20.78 \pm 2.42$ c C & $29.72 \pm 1.36$ a A & $24.05 \pm 2.70 \mathrm{c} \mathrm{B}$ \\
\hline \multicolumn{2}{|c|}{$\begin{array}{l}\text { ID\%/parameter response for each line at } \\
\text { the end of } 12 \text { th generation }\end{array}$} & -20.84 & -15.84 & +22.81 & -13.27 \\
\hline \multirow{6}{*}{$\begin{array}{l}\text { Preying potential of female } \\
\text { (P. citri nymphs/day) }\end{array}$} & Po & $37.54 \pm 7.83$ a A & $35.82 \pm 3.74$ a A & $36.31 \pm 5.89$ a A & $35.82 \pm 3.74$ a A \\
\hline & F1 & $\begin{array}{l}35.28 \pm 3.80 \mathrm{ab} \\
\mathrm{A}\end{array}$ & $34.21 \pm 4.85$ a A & $35.68 \pm 4.02$ a A & $35.43 \pm 4.28$ a A \\
\hline & F3 & $\begin{array}{l}33.38 \pm 3.20 b c \\
B C\end{array}$ & $31.07 \pm 4.73 \mathrm{~b} \mathrm{C}$ & $36.40 \pm 4.38$ a A & $34.30 \pm 3.96 \mathrm{ab} A B$ \\
\hline & F6 & $\begin{array}{l}32.40 \pm 3.10 \mathrm{bcd} \\
\mathrm{B}\end{array}$ & $26.48 \pm 4.90$ c C & $36.83 \pm 5.26$ a A & $32.48 \pm 3.45 b c B$ \\
\hline & F9 & $\begin{array}{l}31.85 \pm 3.04 \mathrm{~cd} \\
\text { B }\end{array}$ & $26.33 \pm 4.41$ c C & $36.39 \pm 4.37$ a $A$ & $31.62 \pm 3.84 \mathrm{CB}$ \\
\hline & $\mathrm{F} 12$ & $29.39 \pm 3.19 \mathrm{~d} \mathrm{~B}$ & $25.86 \pm 4.64$ c C & $36.61 \pm 4.38$ a A & $31.76 \pm 1.43$ bc B \\
\hline \multicolumn{2}{|l|}{$\begin{array}{l}\text { ID\%/parameter response for each line } \\
\text { at the end of } 12 \text { th generation }\end{array}$} & -21.71 & -27.81 & +0.83 & -11.33 \\
\hline \multirow{6}{*}{$\begin{array}{l}\text { Larval developmental period ( } \mathrm{LI}- \\
\text { L4) }\end{array}$} & Po & $14.87 \pm 2.08$ a A & $13.87 \pm 2.30$ a A & $13.63 \pm 1.77$ a A & $12.17 \pm 1.70 \mathrm{C} \mathrm{B}$ \\
\hline & F1 & $\begin{array}{l}13.97 \pm 1.69 \mathrm{ab} \\
\mathrm{A}\end{array}$ & $13.53 \pm 1.61 \mathrm{ab} \mathrm{A}$ & $12.93 \pm 1.78 \mathrm{ab} \mathrm{A}$ & $13.77 \pm 1.76 \mathrm{~b} \mathrm{~A}$ \\
\hline & F3 & $\begin{array}{l}13.53 \pm 1.61 \mathrm{bc} \\
\mathrm{B}\end{array}$ & $13.20 \pm 1.69 \mathrm{ab} \mathrm{BC}$ & $12.17 \pm 1.34 \mathrm{~b} \mathrm{C}$ & $14.80 \pm 1.69 \mathrm{ab} A$ \\
\hline & F6 & $\begin{array}{l}12.93 \pm 1.66 \mathrm{bc} \\
\mathrm{B}\end{array}$ & $12.40 \pm 1.45 \mathrm{~b} \mathrm{~B}$ & $12.23 \pm 1.50 \mathrm{~b} \mathrm{~B}$ & $14.83 \pm 1.15 \mathrm{ab} A$ \\
\hline & F9 & $\begin{array}{l}12.70 \pm 1.90 \mathrm{bc} \\
B\end{array}$ & $12.37 \pm 1.52 \mathrm{~b} \mathrm{~B}$ & $12.20 \pm 1.37 \mathrm{~b} \mathrm{~B}$ & $14.73 \pm 1.05 \mathrm{ab} \mathrm{A}$ \\
\hline & $\mathrm{F} 12$ & $12.63 \pm 1.61 \mathrm{CB}$ & $12.33 \pm 1.54 \mathrm{~b} \mathrm{~B}$ & $12.33 \pm 1.40 \mathrm{~b} \mathrm{~B}$ & $15.07 \pm 1.55$ a A \\
\hline \multicolumn{2}{|l|}{$\begin{array}{l}\text { ID\%/parameter response for each } \\
\text { line at the end of } 12 \text { th generation }\end{array}$} & -15.06 & -11.10 & -9.54 & +23.83 \\
\hline \multirow{6}{*}{$\begin{array}{l}\text { Developmental period } \\
\text { (Egg-adult)/days }\end{array}$} & Po & $30.53 \pm 2.21$ a A & $30.30 \pm 2.22$ a A & $29.10 \pm 2.60 \mathrm{~b} \mathrm{~A}$ & $29.63 \pm 2.06 \mathrm{~b} \mathrm{~A}$ \\
\hline & F1 & $30.77 \pm 2.11$ a A & $30.80 \pm 1.99$ a A & $29.53 \pm 2.32 \mathrm{~b} \mathrm{~A}$ & $30.23 \pm 2.30 \mathrm{ab} \mathrm{A}$ \\
\hline & F3 & $30.23 \pm 1.77$ a A & $30.20 \pm 2.70$ a A & $29.97 \pm 1.83 \mathrm{ab} \mathrm{A}$ & $31.23 \pm 2.13$ a A \\
\hline & F6 & $30.17 \pm 1.84$ a A & $30.77 \pm 2.62$ a A & $30.43 \pm 1.76 \mathrm{ab} \mathrm{A}$ & $31.27 \pm 2.08$ a A \\
\hline & F9 & $30.10 \pm 2.40$ a A & $31.00 \pm 1.31$ a A & $31.20 \pm 1.88$ a A & $31.13 \pm 1.66$ a A \\
\hline & $\mathrm{F} 12$ & $30.13 \pm 2.69$ a A & $31.10 \pm 1.27$ a A & $31.27 \pm 2.32$ a A & $31.43 \pm 1.43$ a A \\
\hline \multicolumn{2}{|l|}{$\begin{array}{l}\text { ID\%/parameter response for each line } \\
\text { at the end of } 12 \text { th generation }\end{array}$} & -1.31 & +2.64 & +7.46 & +6.07 \\
\hline
\end{tabular}

at the end of 12th generation

depression in the control line with significant differences in all studied generations.

The value of reproduction increased significantly from 126.43 in Po to 174.20 at F12; the response for this selection line recorded +37.78 to approach the inbreeding depression of this indicator in the control line.

This significant increase in reproduction indicator was a result of the positive correlation between the 




Fig. 1 Changes in the fecundity according to the change of genetic improved lines

fecundity and reproductive indicator $(0.99$ and +0.76 , respectively) (Table 2).

As for the survival rate trait, this genetic improvement line did not affect significantly the numerical changes of its values during the studied generations. The response was $-2.09 \%$ at the end of F12, despite the positive correlation between fecundity and survival rate at $0.01 \%$ were + 0.73 and 0.56 at Po and F12 in the control line, respectively (Tables 1 and 2). This correlation contributed to maintain the values of this indicator from depression compared with the control line and response was $(-7.66 \%)$ at F12.

Statistical analysis showed that this improvement line could not raise the values of other traits (preying potential of $3^{\text {rd }}$ larval instar, preying potential of female, and larval developmental period). In addition, it could not even keep this trait from depression and was close to control line, and their response of this line were -15.84 , -27.81 , and $-11.10 \%$, respectively, compared with control line $-20.84,-21.71$, and $-15.06 \%$, respectively.
For the development period trait, despite the positive increase achieved by this improved line and response recording (2.64\%), compared to the control line $(-1.31 \%)$ and insignificant differences through studied generations, but this increase was in favor of an increase in the eggs and pupal stages, which are non-predatory and non-economic stages.

\section{Changes in morphobiological parameters of $C$. montrouzieri for the second quantitative trait (preying potential of the $3^{\text {rd }}$ larval instar) through inbreeding in 12 generations}

Results in Table 1 and Figs. 1, 2 and 3 showed that the recurrent selection of this trait for 12 inbreeding generations contributed to the increase of the values of preying potential of the $3^{\text {rd }}$ larval instar with significant differences from 24.20 nymphs/day in Po to 27.03 at F3 and to 28.18 at F9 and with insignificant differences between F9 and F12. The preying potential of the $3^{\text {rd }}$

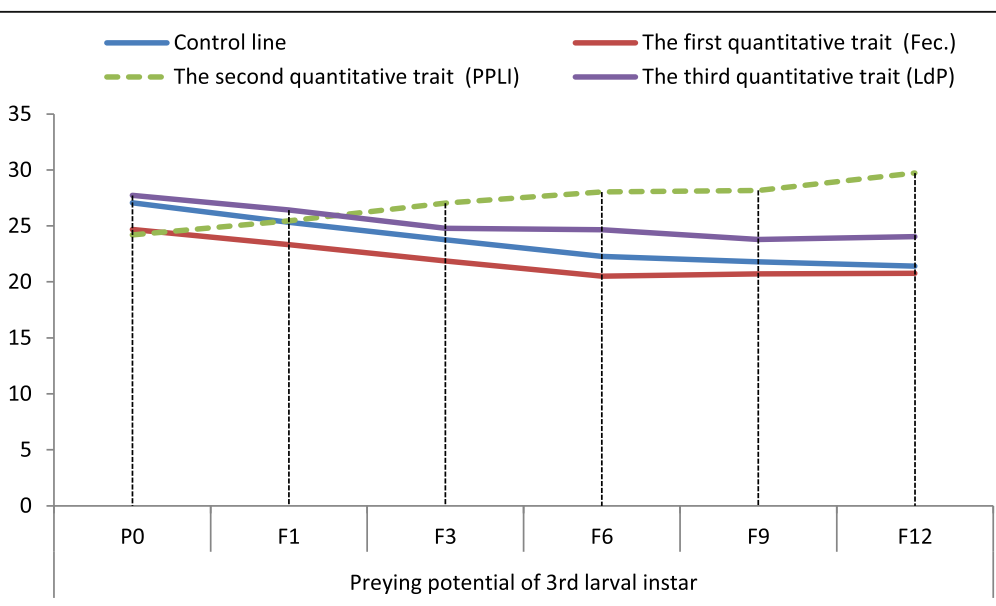

Fig. 2 Changes in the preying potential of $3^{\text {rd }}$ larval instar ( $P$. citri nymphs/day) according to the change of genetic improved lines 


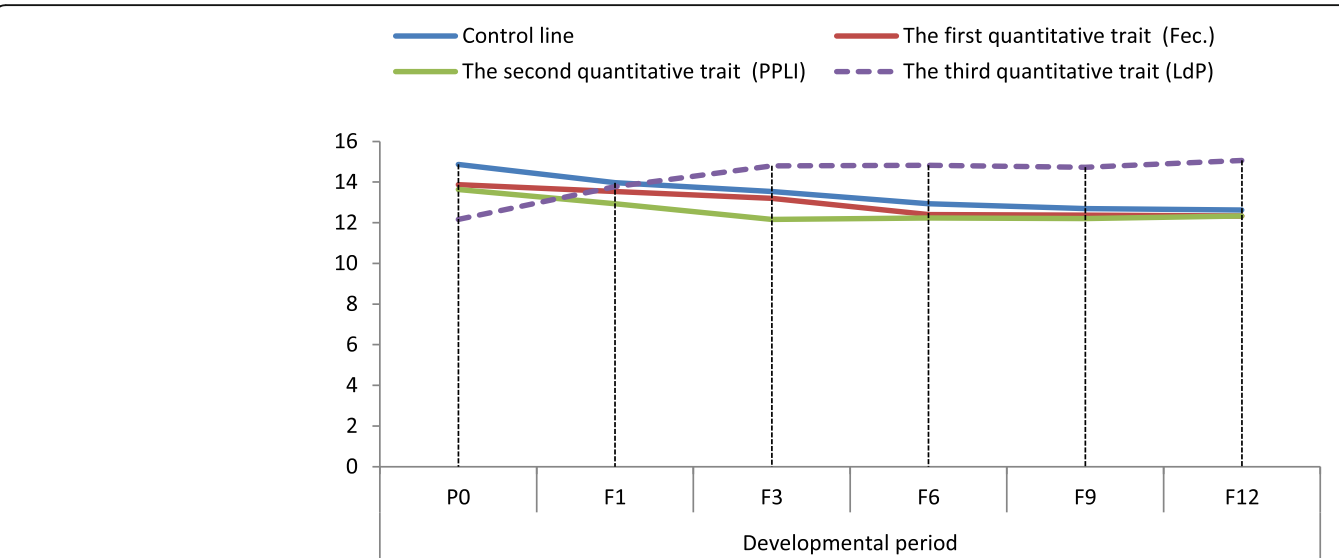

Fig. 3 Changes in the developmental period according to the change of genetic improved lines

larval instar response to selection recorded $+22.81 \%$ at the end of F12 and was almost equal to the inbreeding depression in control line, recording $-20.84 \%$.

Despite the positive correlation between preying potential of the $3^{\text {rd }}$ larval instar and preying potential of female, recording +0.44 and +0.32 in Po and F12 in control line, respectively (Table 2). This did not affect the improvement of the numerical values of this indicator, and the differences remained insignificant through the studied generations. The positive effect of this selection was to maintain the values of this indicator of depression when compared with the control line.

For the other traits (female length, fecundity, reproduction, survival rate, larval developmental period), their values were decreased significantly from Po to F12, similar to the control line.
For developmental period, despite its height and significant differences from Po to F12, this increase was not real and unimportant, because the developmental period increased, while the larval developmental period decreased. The increase was in favor of resting stages and non-predatory.

\section{Changes in morphobiological parameters of $C$. montrouzieri in the third quantitative trait (larval developmental period) through inbreeding in 12 generations}

Results in Table 1 and Figs. 1 and 3 showed that the recurrent selection of this trait for 12 inbreeding generations was contributed to the increase of the value of larval developmental period with significant differences. The value of this trait increased from 12.17 days in Po

Table 2 Correlation relationships between quantitative traits of C. montrouzieri during Po and F12 in the control line

\begin{tabular}{|c|c|c|c|c|c|c|c|c|}
\hline Parameter & Gs & Female length (mm) & $\begin{array}{l}\text { Fecundity } \\
\text { Larvae/female }\end{array}$ & Reproduction & $\begin{array}{l}\text { Survival rate } \\
\%\end{array}$ & PPLI & PPAF & LDP \\
\hline \multirow{2}{*}{$\begin{array}{l}\text { Fecundity } \\
\text { Lavae/female }\end{array}$} & PO & $+0.81^{* *}$ & & & & & & \\
\hline & $\mathrm{F} 12$ & $+0.63^{* *}$ & & & & & & \\
\hline \multirow[t]{2}{*}{ Reproduction } & PO & $+0.78^{* *}$ & $+0.99^{* *}$ & & & & & \\
\hline & $\mathrm{F} 12$ & $+0.55^{* *}$ & $+0.76^{* *}$ & & & & & \\
\hline \multirow[t]{2}{*}{ Survival rate \% } & PO & $+0.45^{*}$ & $+0.73^{* *}$ & $+0.79^{* *}$ & & & & \\
\hline & $\mathrm{F} 12$ & $+0.40^{*}$ & $+0.56^{* *}$ & $+0.61^{* *}$ & & & & \\
\hline \multirow[t]{2}{*}{ PPLI } & PO & -0.35 & $-0.52^{* *}$ & $-0.53^{* *}$ & $-0.44^{*}$ & & & \\
\hline & $\mathrm{F} 12$ & -0.31 & $-0.38^{*}$ & $-0.40^{*}$ & $-0.37^{*}$ & & & \\
\hline \multirow[t]{2}{*}{ PPAF } & PO & -0.31 & $-0.46^{*}$ & $-0.47^{* *}$ & -0.32 & $+0.44^{*}$ & & \\
\hline & $\mathrm{F} 12$ & -0.26 & -0.33 & $-0.37^{*}$ & $-0.38^{*}$ & +0.32 & & \\
\hline \multirow[t]{2}{*}{ LDP } & PO & -0.11 & -0.28 & -0.30 & $-0.39^{*}$ & +0.26 & +0.14 & \\
\hline & $\mathrm{F} 12$ & -0.10 & -0.17 & -0.22 & -0.33 & +0.15 & +0.10 & \\
\hline \multirow[t]{2}{*}{ DP } & PO & -0.09 & -0.15 & -0.12 & -0.10 & +0.12 & +0.25 & $+0.37^{*}$ \\
\hline & $\mathrm{F} 12$ & -0.06 & -0.19 & -0.20 & -0.22 & +0.07 & +0.16 & +0.30 \\
\hline
\end{tabular}


to 13.77 days at F1 and to 14.80 days at F3. The differences remained insignificant between F3 and F9 and increased to 15.07 days at F12 with significant differences. The first segregation generation was the most important generation in showing the value of this attribute and its response to the line of selection and was $+23.83 \%$ at F12.

The significant increase in the value of the development period was from 29.63 days in Po to 31.43 days at F12 due to the positive correlation between these two indicators and was +0.37 and +0.30 in Po and F12, respectively (Table 2).

For the other traits (female length, fecundity, reproduction, survival rate, preying potential of the $3^{\text {rd }}$ larval instar, preying potential of female), the values of these indicators decreased significantly from Po to F12, similar to the control line.

The genetic effect in raising predator indicator values appeared either directly in cases where the indicator was used within its own genetic improved line (fecundity, preying potential of the $3^{\text {rd }}$ larval instar, and larval developmental period) or indirectly through positive correlation (between indicators) within the same improvement line, while every genetic improved line did not affect to the raising of other indicators when compared to control and other improved lines (Table 1) and Figs. 1, 2 and 3).

The inbreeding can have a number of negative effects in many quantitative traits and is related to loss of heterozygosity or to increase the expression of recessive alleles (Charlesworth and Charlesworth 1999). Obtained results agree with several researchers about inbreeding depression that has been demonstrated to negative affection in many quantitative traits of insect, female fecundity (Henter 1993; Tanaka 1993; Roff and DeRose 2001; Van Oosterhout et al. 2000), adult size (e.g., Armbruster et al. 2000; Reale and Roff 2003) and larval development time (Morjan et al. 1999; Roff 1998). Fox and Scheibly (2006) reported that the seed beetle Stator limbatus exhibited substantial inbreeding depression at all stages of development. Eggs from sib mating were less likely to develop and hatch, and larval mortality was higher and development time longer for offspring of sib mating. Nakamura (1996) stated that decreases in adult emergence and host mortality were observed after two generations of inbreeding in the fly Exorista japonica, and Al-Khateeb et al. (2012) reported that the most morphobiological parameters of C. montrouzieri were significantly reduced after six generations of inbreeding but inbreeding is not always disadvantageous, because it leads to greater genetic variance among progenies and may increase the expected genetic gain with selection (Falconer 1989; Jervis 2007; Paterniani and Miranda Filho 1987).

\section{Correlation between the most important quantitative traits of the predator $C$. montrouzieri}

Results in Table 2 showed that there were positive significant correlations between fecundity and each of length of female, reproduction, and survival rate during Po and F12 which were $+0.81,+0.63,+0.99,0.76,0.73$, and 0.56 , respectively, and negative correlation between fecundity and other indicators (preying potential of the $3^{\text {rd }}$ larval instar, preying potential of female, larval development period and development period) during Po and F12 which were $-0.516,-0.38,-0.46,-0.33$, $-0.28,-0.17,-0.15$, and -0.19 , respectively.

As shown in Table 2, the studied quantitative traits can be categorized into three groups:

1. The first group included the important indicators that have positive correlations among them (fecundity, female length, reproduction, and survival rate) and concerned with the expression of the fecundity.

2. The second group concerned with the expression of the feeding potential represented in the (preying potential of the $3^{\text {rd }}$ larval instar and preying potential of female) with superiority to the preying potential of the $3^{\text {rd }}$ larval instar. This is an important trait for predatory insects that are used in integrated pest management program.

3. The third group concerned with the expression of larval development period and development period traits. The larval development period showed a greater advantage in the extent to which it fluctuate values. It was the real predatory stage and represented the predation economic age, while the development period was moved away from the practical expression of this concept due to the existence of the resting, non-economic and non-predation phases (egg and pupal stage).

Fecundity is an important life history trait in understanding population dynamics, because it is one of the bases from which population changes are determined through the incidence of environmental factors (Honek 1993; Richerson et al. 1978). Therefore, fecundity was served as the primary trait in the research. The relationship between fecundity and adult body size in many insects has been studied (Honek 1993). Obtained results agree with Honek (1986) who reported that in insects, there is a strong positive correlation between female size and its fecundity, reproduction, and survival, and with Zheng et al. (1993) who stated that in predators, larger females have a shorter preoviposotional period than smaller ones and this may contribute to their higher fecundity. 
Obtained results agree with the finding of Asslan et al. (2008) who stated that the fecundity of the predator Coccinella septempunctata was correlated positively with the female length, reproduction, and survival rate. The correlation coefficient between them was $+0.8,+0.7$, and 0.5 , respectively, and Al-Khateeb (2013) reported that the fecundity of the predator $C$. montrouzieri was correlated positively with each of adult size, reproduction, and survival and the correlation coefficient between them was $+0.91,+$ 0.99 , and +0.63 , respectively in the parent generation.

Results presented in Table 3 showed that the phenotypic variance was higher than the genotypic one in the control line for fecundity trait and was 1019.09 and 483.48, respectively. Similarly, the phenotypic variation coefficient was higher than the genetic variation coefficient and was 30.39 and $20.93 \%$, respectively. The broad sense heritability ( $\mathrm{h}^{2} \mathrm{bs}$ ) was $47.43 \%$ which was a moderate percentage and that had an environmental impact.

When the fecundity was introduced in the genetic improved line within inbreeding program, the genetic variation coefficient (GCV) increased (12.16\%) compared with the (PCV) $(15.24 \%)$ and $h^{2}$ bs increased to $63.70 \%$ which was higher and was confirmed as the high genetic balance of this trait to determine the phenotypes of its individuals.

The positive significant correlation between fecundity and each of length of female, reproduction, and survival rate, during Po and F12, which were $+0.81,+0.63 ;+0.99$ ,+ 0.76 ; and $+0.73,+0.56$ (Table 2 ), respectively, increased the value of these traits together when subjecting them to breeding and selection programs (direct or multiple quantitative traits). Obtained results agree with the finding of Falconer and Mackay (1996) and Jervis (1997) who stated that the high values of the genetic variation coefficient of quantitative traits indicate that it can be used as a selection tool based on the phenotypic expression of these traits because the difference between the phenotypic variation coefficient and the genetic variation coefficient is low and thus increases the chances of selection and the possibility of genetic improvement. Jervis (2007) reported that the higher the GCV value, the higher the probability of the success of selection.

Statistical analyses showed that the $\mathrm{h}^{2} \mathrm{bs}$ increased from $(31.66 \%)$ in control line to $(40.80 \%)$ in the second quantitative trait (preying potential of the $3^{\text {rd }}$ larval instar) (Table 3). This reflected the medium genetic stock and the effect of the environmental factors controlling the expression of this trait. The positive significant correlation between preying potential of the $3^{\text {rd }}$ larval instar and preying potential of the female will increase the value of this indicator when this trait included in genetic improvement programs.

As for the larval developmental period, there were differences between the value of genetic variance and phenotypic variation in the control line and were $(0.65$, 3.77), respectively. These differences were reflected in the values of the PCV \%, GCV\% and $\mathrm{h}^{2}$ bs and were $14.45,6.0$, and $17.27 \%$, respectively.

These differences remained significant in the artificial selection program (third line) through 12 inbreeding generations. Despite a slight improvement in $\mathrm{h}^{2} \mathrm{bs}$, it remained low and was $33.50 \%$. This indicates the significant impact of environmental factors on the expression of this trait and its genetic stock was low. In order to improve this trait, it must be used in the selection index/artificial selection. Estimate the level of heritability $h^{2} b s$ is the most important genetic value in

Table 3 Estimation of the important genetic parameters of quantitative traits included in the artificial index of C. montrouzieri among 12 generations of inbreeding

\begin{tabular}{|c|c|c|c|c|c|c|}
\hline \multirow[t]{2}{*}{ Parameter } & \multicolumn{3}{|c|}{ Control line } & \multirow{2}{*}{$\begin{array}{l}\text { First genetic } \\
\text { improved line } \\
\text { (Fec.) } \\
\text { Fec. }\end{array}$} & \multirow{2}{*}{$\begin{array}{l}\text { Second genetic } \\
\text { improved line } \\
\text { (PPLI) } \\
\text { PPLI }\end{array}$} & \multirow{2}{*}{$\begin{array}{l}\text { Third genetic } \\
\text { improved line } \\
(\mathrm{LdP}) \\
\mathrm{LdP}\end{array}$} \\
\hline & Fec. & PPLI & $\mathrm{LdP}$ & & & \\
\hline MST & $15,040.13$ & 147.88 & 22.66 & $13,411.54$ & 120.31 & 36.69 \\
\hline$V_{G}$ & 483.48 & 4.60 & 0.65 & 438.71 & 3.83 & 1.15 \\
\hline$V_{E}$ & 535.81 & 9.93 & 3.12 & 250.13 & 5.54 & 2.28 \\
\hline$V p$ & 1019 & 14.52 & 3.77 & 688.85 & 9.37 & 3.42 \\
\hline SD & 31.93 & 3.81 & 1.94 & 26.25 & 3.06 & 1.85 \\
\hline$x$ & 105.07 & 23.60 & 13.44 & 172.26 & 27.11 & 14.30 \\
\hline GCV\% & 20.93 & 9.09 & 6.00 & 12.16 & 7.21 & 7.49 \\
\hline ECV\% & 22.03 & 13.35 & 13.14 & 9.18 & 6.68 & 10.55 \\
\hline PCV\% & 30.39 & 16.15 & 14.45 & 15.24 & 11.29 & 12.49 \\
\hline$h^{2}$ bs $\%$ & 47.43 & 31.66 & 17.27 & 63.70 & 40.80 & 33.50 \\
\hline
\end{tabular}

Fec. fecundity, PPLI preying potential of $3^{\text {rd }}$ larval instar, LdP larval developmental period, MST mean squares between generations, $V_{G}$ genetic variance, $V_{E}$ environmental variance, $S D$ standard division $X$ mean, $P C V \%$ phenotypic coefficient of variation, GCV\% genotypic coefficient of variation and, ECV\% environmental coefficient of variation, $h^{2}$ bs broad sense heritability 
order to include and represent it in the artificial selection: a low $h^{2}$ bs (less than 0.4), a moderate $h^{2}$ bs 0.4-0.6, and a high $\mathrm{h}^{2} \mathrm{bs}$ (greater than 0.6).

\section{Constructing equation of selection index/artificial selection}

The construction of the selection index included three quantitative traits (fecundity, preying potential of the $3^{\text {rd }}$ larval instar, and the larval developmental period). Fecundity was served as the primary trait in the research.

$$
\begin{aligned}
I & =\mathrm{b} 1 \times 1+\mathrm{b} 2 \times 2+\mathrm{b} 3 \times 3 \\
b & =P^{-1} G v \\
\mathrm{~b} 1 & =(688.85)^{-1}(438.71)(1) \\
\mathrm{b} 1 & =0.637=0.64 \\
\mathrm{~b} 2 & =(9.37)^{-1}(3.83)(8.58) \\
\mathrm{b} 2 & =3.502=3.5 \\
\mathrm{~b} 3 & =(3.42)^{-1}(1.15)(14.18) \\
\mathrm{b} 3 & =4.751=4.75 \\
I & =0.64(\mathrm{x} 1)+3.50(\mathrm{x} 2)+4.75(\mathrm{x} 3)
\end{aligned}
$$

Results in Table 4 showed that the relative economic values of the three quantitative traits (fecundity, preying potential of the $3^{\text {rd }}$ larval instar, and the larval developmental period) were $1,8.58$, and 14.18 , respectively.

After solving the system of normal equations, the selection index was termed:

$I=0.64(\mathrm{x} 1)+3.50(\mathrm{x} 2)+4.75(\mathrm{x} 3)$, while $I$ was the index value and $\mathrm{b} 1=0.64, \mathrm{~b} 2=3.50$, and $\mathrm{b} 3=4.75$ were the index weights and refer to the three studied quantitative traits (Table 4). $\mathrm{x} 1, \mathrm{x} 2$, and $\mathrm{x} 3$ are phenotypic information sources and also refer to the studied quantitative traits, respectively.

\section{Conclusions}

The created artificial selection can serve as a simple and fast way to rank the predator and can be applied it in the next genetic improvement programs of C. montrouzieri, according to its high value to be parents for consecutive generations. Based on the results of this research and the correlation relations that were organized, according to the three groups, the use of these traits in the artificial selection may allow the other traits to be raised and the fecundity trait, which was served as

Table 4 Economic values of the fecundity, between preying potential of the $3^{\text {rd }}$ larval instar and the larval developmental period

\begin{tabular}{lllll}
\hline Trait & $V p$ & $V_{p}$ & REV & $b$ \\
\hline Fec. & 688.85 & 26.25 & 1 & 0.64 \\
PPLI & 9.37 & 3.06 & 8.58 & 3.5 \\
LdP & 3.42 & 1.85 & 14.18 & 4.75 \\
\hline
\end{tabular}

$b$ economic value, $V p$ phenotypic variance, $R E V$. relative economic values, Fec. Fecundity, PPLI preying potential of $3^{\text {rd }}$ larval instar, LdP larval developmental period the primary trait in the research, leads to the removal and coverage of the defects of both traits (preying potential of the $3^{\text {rd }}$ larval instar and the larval developmental period), and thus was the best way to raise the most important indicators of the bio-efficiency of the predator.

\section{Authors' contributions}

All authors read and approved the final manuscript.

Ethics approval and consent to participate

Not applicable.

Competing interests

The authors declare that they have no competing interests.

\section{Publisher's Note}

Springer Nature remains neutral with regard to jurisdictional claims in published maps and institutional affiliations.

\section{Author details}

${ }^{1}$ Directorate of Agriculture, Department of Biological Control, Lattakia Center for Rearing Natural Enemies, P. O. Box 2012, Lattakia, Syria. ${ }^{2}$ Faculty of Agriculture, Damascus University, Damascus, Syria. ${ }^{3}$ Department of Biological Control, Plant Protection Research Institute, Agricultural Research Center, Giza, Egypt.

Received: 21 February 2018 Accepted: 3 May 2018

Published online: 16 May 2018

\section{References}

Al-Khateeb N (2013) Rearing and Propagation of Cryptolaemus montrouzieri Mulsant (Coleoptera: Coccinellidae) by Random Allogamy and Study its Effect on Certain Morphobiological Parameters of the Predator, Damascus University Publication, Syria. M Sc., Thesis pp 166

Al-Khateeb N, Asslan L (2007) Determination of the most important biological indicators of the predator, Nephus includens Kirch as compared with those of the predator, Cryptolaemus montrouzieri. Research Journal of Damascus University 23(2):121-134

Al-Khateeb N, Asslan L, El-Heneidy AH, Bashee A (2012) Effect of random allogamy and inbreeding (brother-sister) mating on some morphobiological parameters of the Syrian laboratory strain of Cryptolaemus montrouzieri Mulsant (Coleoptera: Coccinellidae). Egyptian Journal of Biological Pest Control 22(2):197-204

Al-Khateeb N, Raie A (2002) A study of some biological parameters of the predator Cryptolaemus montrouzieri Mulsant introduced to Planococcus citri Risso in Syria, and estimate its predation rate in laboratory. Arab Journal of Plant Protection 19(2):131-135

Armbruster P, Hutchinson RA, Linvell T (2000) Equivalent inbreeding depression under laboratory and field conditions in a tree-hole-breeding mosquito. Proc R Soc Lond B 267:1939-1945

Asslan L, Al-Khateeb N, El-Heneidy A (2008) Testing the extent of genetic build response of Coccinella septempunctata $(\mathrm{L}$.) to genetic improvement by random allogamy. Egyptian Journal of Biological Pest Control 18(2):353-359

Bartlett BR (1974) Introduction into California of cold-tolerant biotypes of the mealy bug predator, Cryptolaemus montrouzieri, and laboratory procedures for testing natural enemies for cold-hardine6ss. Environ Entomol 3(3):553-556

Charlesworth D, Charlesworth B (1999) The genetic basis of inbreeding depression. Genet Res 74:329-340

Dixon AFG (2000) Insect predator-prey dynamics: ladybird beetles and biological control, pp. 257. Cambridge University Press, Cambridge

Falconer DS (1989) Introduction to quantitative genetics, $3^{\text {rd }}$ edn. Longman, New York, p 365

Falconer DS, Mackay TFC (1996) Introduction to quantitative genetics, 4th edn. Pearson, United Kingdom, p 480

Fox CW, Scheibly KL (2006) Variation in inbreeding depression among populations of the seed beetle, Stator limbatus Entomologia experimentalis et applicata 121(2):137-144. 
Hazel LN (1943) The genetic basis of constructing selection indices. Genet 28: $476-490$

Henter HJ (1993) Inbreeding depression and haplodiploidy: experimental measures in a parasitoid and comparisons across diploid and haplodiploid insect taxa. Evolution 57:1793-1803

Honek A (1986) Production of feces in natural populations of aphidophagous coccinellids (Col.) and estimation of predation rates. J Appl Entomol 102(1-5):467-476

Honek A (1993) Intraspecific variation in body size and fecundity in insects: a general relationship. Oikos 66:483492

Hufbauer RA, Roderick GK (2005) Microevolution in biological control: mechanisms, patterns, and processes. Biol Control 35:227-239

Jayaraman V, Chandramohan N, Gopalan M (1988) Balasubramanian G. Predatory potential of coccinellid beetles on mealybugs of citrus and grapevine. Madras Agricultural Journal 75:77-78

Jervis MA (1997) Parasitoids as limiting and selective factors: can biological control be evolutionarily stable? Trends in Ecology and Evolution 12:378-379

Jervis MA (2007) Insects as natural enemies: a practical perspective. In: ISBN-10 1-4020-1734-0 (HB) springer. Dordrecht, Berlin, Heidelberg, New York 723 pp

McDonald BA (1997) The population genetics of fungi: tools and techniques. Phytopathology 87:448-453

Morjan WE, Obrycki JJ, Krafsur ES (1999) Inbreeding effects on Propylea quatuordecimpunctata (Coleoptera: Coccinellidae). Ann Entomol Soc Am 92:260-268

Nakamura S (1996) Inbreeding and rotational breeding of the parasitoid fly, Exorista japonica (Diptera: Tachinidae), for successive rearing. Appl Entomol Zool 31:433-441

Oncuer C, Bayhan N (1982) An investigation into the feeding capacity and diet of Cryptolaemus montrouzieri (Muls.). Turkiye Bitki Koruma Dergisi 6(2):85-90

Oupadissakoon S, Wersman EA (1977) Agronomic performance and nature of gene effects progenitor species-derived genotypes and tobacco. Crop Sci 17: 843-847

Paterniani, E., Miranda Filho, J. B.. 1987. "Populations breeding." Breeding and population of corn. Campinas: Fundação Cargill, 217-264.p

Phillips CB, Baird DB, Lline LL, McNeill MR, Proffitt JR, Goldson SL, Kean JM (2008) East meets west: adaptive evolution of an insect introduced for biological control. J Appl Ecol 45:948-956

Reale D, Roff DA (2003) Inbreeding, developmental stability, and canalization in the sand cricket Gryllus firmus. Evolution 57:597-605

Richerson JV, Cameron EA, White DE, Walsh M (1978) Egg parameters as a measure of population quality of the gypsy moth, Lymantria dispar. Ann Entomol Soc Am 71:6064

Roff DA (1998) Effects of inbreeding on morphological and life history traits of the sane cricket, Gryllus firmus. Heredity 81:28-37

Roff DA, DeRose MA (2001) The evolution of trade-offs: effects of inbreeding on fecundity relationships in the cricket, Gryllus firmus. Evolution 55:111-121

Routray S, Dey D, Baral S, Das AP, Mahantheshwara B (2016) Genetic improvement of natural enemies. A review Agricultural Reviews 37(4):325-332

Rutledge CE, Wiedenmann RN (2003) An attempt to change habitat preference of a parasitoid, Cotesia sesamiae (Hymenoptera: Braconidae), through artificial selection. J Entomol Sci 38:93-103

Simmonds MSJ, Manlove JD, Blaney WM, Khambay BPS (2000) Effect of botanical insecticides on the foraging and feeding behavior of the coccinellid predator Cryptolaemus montrouzieri. Phytoparasitica 28:99-107

Singh RK, Chaudhary BD (1985) Biometrical methods in quantitative genetic analysis. Kalyani Publishers, New Delhi, pp 39-78

Smith HS, Armitage HM (1931) The biological control of mealy bugs attacking citrus. California University Agricultural Station. Bulletin 509, p 74

Tanaka Y (1993) A genetic mechanism for the evolution of senescence in Callosobruchus chinensis (the azuki bean weevil). Heredity 70:318-321

Van Oosterhout C, Zijlstra WG, van Heuven MK, Brakefield PM (2000) Inbreeding depression and genetic load in laboratory metapopulations of the butterfly, Bicyclus anynana. Evolution 54:218-225

Whitcomb WH, Bell K (1964) Predaceous insects, spiders and mites of Arkansas cotton fields. University of Arkansas Agricultural Experiment Station, p 84 Bulletin 690

Zheng J, Knighton DR, Xuong NH, Taylor SS, Sowadski JM, Ten Eyck LF (1993) Crystal structure of the myristylated catalytic subunit of CAMP-dependent protein kinase reveal open and closed conformations. Protein Sci 10:1559-1573

\section{Submit your manuscript to a SpringerOpen ${ }^{\odot}$ journal and benefit from:}

- Convenient online submission

- Rigorous peer review

- Open access: articles freely available online

- High visibility within the field

- Retaining the copyright to your article

Submit your next manuscript at $\gg$ springeropen.com 